\title{
Radiation protection in digestive endoscopy: European Society of Digestive Endoscopy (ESGE) Guideline
}

Authors

Institutions
J.-M. Dumonceau' ${ }^{1}$, F. J. Garcia-Fernandez ${ }^{2}$, F. R. Verdun ${ }^{3}$, E. Carinou ${ }^{4}$, L. Donadille ${ }^{5}$, J. Damilakis ${ }^{6}$, I. Mouzas ${ }^{7}$, K. Paraskeva ${ }^{8}$, N. Ruiz-Lopez ${ }^{3}$, L. Struelens ${ }^{9}$, V. Tsapaki ${ }^{10}$, F. Vanhavere ${ }^{9}$, V. Valatas ${ }^{7}$, M. Sans-Merce ${ }^{3}$

Institutions are listed at the end of article.

\section{Bibliography}

DOI http://dx.doi.org/

10.1055/s-0031-1291791

Endoscopy 2012; 44: 408-424

(c) Georg Thieme Verlag KG

Stuttgart · New York

ISSN 0013-726X

\section{Corresponding author}

J.-M. Dumonceau, MD PhD

Division of Gastroenterology and Hepatology

Geneva University Hospitals

Rue Gabrielle Perret Gentil 4

1211 Geneva

Switzerland

Fax: $+41+22+3729366$

jmdumonceau@hotmail.com
This article expresses the current view of the European Society of Gastrointestinal Endoscopy (ESGE) about radiation protection for endoscopic procedures, in particular endoscopic retrograde cholangiopancreatography (ERCP). Particular cases, including pregnant women and pediatric patients, are also discussed. This Guideline was developed by a group of endoscopists and medical

\section{Introduction}

\section{$\nabla$}

Ionizing radiation is used during diagnostic and therapeutic endoscopic procedures, most frequently during endoscopic retrograde cholangiopancreatography (ERCP). The current Guideline describes the types of X-ray systems that may be used for ERCP, radiation doses commonly reported for diagnostic and therapeutic ERCP, interventions that are effective in reducing radiation doses for the patient and staff members, and legal aspects of radiation protection (RP).

\section{Methods}

$\nabla$

The European Society of Gastrointestinal Endoscopy (ESGE) commissioned and funded this Guideline. The methodology was similar to that used for other ESGE Guidelines [1, 2]. Briefly, subgroups were formed, each charged with a series of clearly defined key questions (see $\bullet$ Appendix e1, available online). The committee chair worked with subgroup speakers to identify pertinent search terms that always included, as a minimum, "radiation" and words pertinent to specific key questions. Evidence tables were generated for each key question based on evidence-based reviews or randomized controlled trials (RCTs) if these were available; otherwise, case-control studies, retrospective analyses, and case series were included. The number of articles retrieved and selected for each task force is indicated in physicists to ensure that all aspects of radiation protection are adequately dealt with. A two-page executive summary of evidence statements and recommendations is provided. The target readership for this Guideline mostly includes endoscopists, anesthesiologists, and endoscopy assistants who may be exposed to X-rays during endoscopic procedures.

the Evidence table (see $\bullet$ Appendix e2, available online). Evidence levels and recommendation grades used in this Guideline were those recommended by the amended Scottish Intercollegiate Guidelines Network ( Table 1), except for wellestablished laws of radiation physics that were considered to be Evidence level $1++[3]$. Subgroups agreed by online communication on draft proposals that were presented to the entire group for general discussion during a meeting held in September 2010.The results of that discussion were incorporated into the subsequent Guideline version and again discussed by email until unanimous agreement was reached. Searches were rerun in February 2011 (this date should be taken into account for future updates) and a final draft was written during a second meeting in August 2011. All members of the Guideline development group approved the final draft; it was sent to all individual ESGE members in September 2011 and, after incorporation of their comments, it was endorsed by the ESGE Governing Board prior to submission to Endoscopy for international peer review. All members of the Guideline development group approved the final revised version before publication.

Technical terms related to radiation that are used in this Guideline are defined in $\bullet$ Table 2. Evidence statements and recommendations are stated in italics; key evidence statements and recommendations are in bold. This Guideline will be considered for revision in 2016, or sooner if important new evidence becomes available. Any up- 
Table 1 Definitions of categories for evidence levels and recommendation grades used in this Guideline [3].

\begin{tabular}{|c|c|}
\hline \multicolumn{2}{|c|}{ Evidence level } \\
\hline $1++$ & $\begin{array}{l}\text { High quality meta-analyses, systematic reviews of RCTs, or RCTs } \\
\text { with a very low risk of bias }\end{array}$ \\
\hline $1+$ & $\begin{array}{l}\text { Well conducted meta-analyses, systematic reviews of RCTs, or } \\
\text { RCTs with a low risk of bias }\end{array}$ \\
\hline $1-$ & $\begin{array}{l}\text { Meta-analyses, systematic reviews, or RCTs with a high risk of } \\
\text { bias }\end{array}$ \\
\hline $2++$ & $\begin{array}{l}\text { High quality systematic reviews of case-control or cohort stud- } \\
\text { ies; high quality case - control studiesor cohort studies with a } \\
\text { very low risk of confounding, bias, or chance and a high prob- } \\
\text { ability that the relationship is causal }\end{array}$ \\
\hline $2+$ & $\begin{array}{l}\text { Well conducted case - control or cohort studies with a low risk of } \\
\text { confounding, bias, or chance and a moderate probability that } \\
\text { the relationship is causal }\end{array}$ \\
\hline $2-$ & $\begin{array}{l}\text { Case - control or cohort studies with a high risk of confounding, } \\
\text { bias, or chance and a significant risk that the relationship is not } \\
\text { causal }\end{array}$ \\
\hline 3 & Nonanalytic studies, e.g. case reports, case series \\
\hline 4 & Expert opinion \\
\hline \multicolumn{2}{|c|}{ Recommendation grade } \\
\hline A & $\begin{array}{l}\text { At least one meta-analysis, systematic review, or RCT rated as } 1+ \\
+ \text { and directly applicable to the target population or a systematic } \\
\text { review of RCTs or a body of evidence consisting principally of } \\
\text { studies rated as } 1 \text { + directly applicable to the target population } \\
\text { and demonstrating overall consistency of results }\end{array}$ \\
\hline B & $\begin{array}{l}\text { A body of evidence including studies rated as } 2++ \text { directly ap- } \\
\text { plicable to the target population and demonstrating overall } \\
\text { consistency of results or extrapolated evidence from studies } \\
\text { rated as } 1++ \text { or } 1+\end{array}$ \\
\hline C & $\begin{array}{l}\text { A body of evidence including studies rated as } 1-\text { or } 2+\text { directly } \\
\text { applicable to the target population and demonstrating overall } \\
\text { consistency of results or extrapolated evidence from studies } \\
\text { rated as } 2++\end{array}$ \\
\hline $\mathrm{D}$ & $\begin{array}{l}\text { Evidence level } 2-, 3 \text { or } 4 \\
\text { or extrapolated evidence from studies rated as } 2+\end{array}$ \\
\hline
\end{tabular}

$\mathrm{RCT}$, randomized controlled trial

dates to the Guideline in the interim period will be noted on the ESGE website: http://www.esge.com/esge-guidelines.html.

\section{Summary of recommendations}

\section{Education and training}

Education programs in RP are mandatory under European Directive and Member States' laws for physicians who use diagnostic Xray, including nonradiologists, to reduce radiation doses to patients while maintaining adequate image quality (Recommendation grade $D)$.

\section{State of knowledge}

Types of X-ray systems

Systems that have the X-ray tube located above or under the patient table are described as "over-couch" or "under-couch" systems, respectively. Mobile X-ray units, also called "mobile C-arm units," are usually used under-couch. For ERCP, both over-couch and undercouch systems are used. The difference between over-couch and under-couch systems is more relevant to healthcare staff than to patients, as which area of a staff member's body receives most radiation exposure depends on which type of system is used. Staff radiation exposure may be significantly higher with mobile C-arm units and over-couch $X$-ray systems compared with stationary under-couch $X$-ray systems (Evidence level $2+$ ).

\section{Radiation doses during ERCP}

The mean entrance skin dose (ESD) during ERCP ranges between 55 and $347 \mathrm{mGy}$ in most studies, with values approximately three times higher for therapeutic compared with diagnostic ERCP. Mean values of kerma - area product (KAP) reported for diagnostic and therapeutic ERCP are in the range of 3-115 $\mathrm{Gy} \cdot \mathrm{cm}^{2}$ and $8-$ $333 \mathrm{~Gy} \cdot \mathrm{cm}^{2}$, respectively (Evidence level $2+$ ). Limited information regarding dose reference levels (DRLS) is available for ERCP. The United Kingdom (UK) and the Nordic RP authorities have proposed $K A P$ values of $20 \mathrm{~Gy} \cdot \mathrm{cm}^{2}$ and $50 \mathrm{~Gy} \cdot \mathrm{cm}^{2}$, respectively. For examinations different from ERCP, recording patient radiation doses at a national level was followed by a decrease in patient radiation exposure (Evidence level 2-). We recommend reporting patient radiation doses in a national database (Recommendation grade $D$ ).

\section{Dosimetric aspects \\ Staff monitoring}

The effective dose $(\mathrm{E})$ is best estimated by wearing two dosimeters: one at the neck, outside of the protective apron, and the other one under the protective apron, at waist level (Evidence level 1-). Radiation doses to the extremities (hands, fingers, legs) are low during ERCP with appropriate RP shielding, compared with recommended radiation dose limits (Evidence level $2+$ ). For staff monitoring, the use of two dosimeters is recommended but a single dosimeter worn under the $R P$ apron can provide a reasonable estimate of $E$ in most cases and may be more practical. If this single dosimeter is worn over the apron it can also provide a good estimation of eye lens doses. With appropriate shielding, monitoring of extremity radiation doses is not needed. When no shielding is available, a sample of test measurements should be obtained to decide whether or not monitoring of extremity radiation doses is needed. (Recommendation grade (). An appropriate algorithm must be used to avoid overestimation or underestimation of $E$ when only one dosimeter is used. With the forthcoming lowering of the recommended radiation dose limit for the eye lens to $20 \mathrm{mSv} / \mathrm{year}$, monitoring of radiation doses at the level of the eye lens will be needed with over-couch systems that do not have adequate RP shielding. (Recommendation grade $D$ ).

\section{Patient dose monitoring}

Among the easily available metrics for radiation exposure, KAP is the best for monitoring patient radiation dose (Evidence level $2++$ ). KAP should be monitored, and its cumulative value should be recorded in the patient file for every ERCP, by either the radiology technician or the attending endoscopist (Recommendation grade $B$ ).

\section{Medical physicist availability}

Endoscopists should have access to the support of a medical physicist to assess radiation doses and to optimize procedures (Recommendation grade $D$ ).

\section{RP measures for staff}

\section{Personal RP measures}

Radiation dose is inversely proportional to the square of the distance from the X-ray source (Evidence level $1^{++}$). Radiation exposure of staff members is significant; highest radiation doses are usually measured at the locations of the endoscopist and of the person monitoring patient sedation (Evidence level 2-). Staff should be positioned as far as possible from the $X$-ray source and from the patient, the source of scattered radiation (Recommendation grade $A$ ). We recommend positioning RP shields to protect all staff members, including the endoscopist and the person monitoring patient sedation (Recommendation grade $D$ ). 
$R P$ aprons with lead-equivalent thickness $\geq 0.25 \mathrm{~mm}$ effectively reduce radiation exposure. Musculoskeletal complaints are frequent amongst endoscopists performing ERCP and may be increased by $R P$ aprons. Radiation exposure of the thyroid gland during ERCP may be significant, in particular when working with unshielded over-couch systems (Evidence level $2+$ ). All persons in the procedure room (except the patient and people in the area behind a stationary shield if available) should wear a wrap-around (not front-only) RP apron and an RP collar with lead-equivalent thickness $\geq 0.25 \mathrm{~mm}$ when $X$-rays are used (Recommendation grade C). An RP apron with a collar attached to it may encourage the use of thyroid shields. RP aprons should be hung vertically, to prevent cracks, in a place that can be reached under the protection of an RP shield (e.g., behind a stationary shield close to the entrance door, or outside the endoscopy room). Moreover, they should be tested annually for defects (Recommendation grade $D$ ).

$R P$ gloves are uncomfortable for ERCP and provide limited X-ray attenuation (Evidence level $2++$ ); they are not recommended during ERCP (Recommendation grade B). Optimal RP of the eyes during fluoroscopy depends heavily upon location of the $X$-ray source and on RP shielding (Evidence level $2++$ ). If an over-couch system is used with no RP shield, all persons in the procedure room except the patient should wear RP glasses with side panels or an RP facemask (Recommendation B).

Staff radiation exposure may be decreased by $\geq 90 \%$ by using $R P$ shields located between the X-ray tube/patient and the staff. Mobile $C$-arm units cause more radiation exposure to staff than stationary $X$-ray units, in part because of the frequent absence of RP shielding attached to these systems (Evidence level $2+$ ). Shields of $\geq 0.5 \mathrm{~mm}$ lead-equivalent thickness should be positioned between the X-ray tube/patient and the staff, including when mobile C-arm units are used (Recommendation grade $\mathrm{C}$ ).

Signs and warnings

Visible alarms (typically, light flashing when fluoroscopy is in progress, and posters that ask patients to inform about possible pregnancy) should be present, close to each door of an endoscopy room where there is a stationary X-ray unit (Recommendation D).

\section{RP shielding of examination rooms}

Appropriate structural shielding is required for stationary $X$-ray units, and should be considered with some mobile C-arm units. Room shielding requirements should be calculated by a medical physicist.

RP measures for the patient

Patient position

Radiation dose is inversely proportional to the square of the distance from the $X$-ray source (Evidence level $1++$ ). Therefore, the patient should be positioned as far as possible from the X-ray tube (i. e., close to the $X$-ray detector) (Recommendation grade $A$ ).

\section{Fluoroscopy parameters}

Measures that decrease patient radiation exposure include: the use of pulsed rather than continuous fluoroscopy (Evidence level 2-), and of time-limited fluoroscopy (Evidence level 1-); avoidance of taking radiographs; increasing the tube voltage (this may decrease image quality) (Evidence level $2+$ ); and collimating $X$-rays to a small field of view (this increases image quality) (Evidence level $1++$ ). It is recommended to use pulsed fluoroscopy with the lowest possible pulse rate, rather than continuous fluoroscopy; to store when possible the "Iast image hold" as an alternative to taking a radiograph; to collimate the X-ray beam to the smallest practical size; to increase tube voltage as far as possible without compromising image quality; and to use magnification modes only if necessary. The use of timelimited fluoroscopy may also be considered if this is not too impractical (Recommendation grade C).

\section{Copper filtration}

A reduction in patient radiation dose of approximately $50 \%$, with reduction in image quality, can be achieved by inserting a copper filter in the X-ray beam (Evidence level 1-). We recommend testing the usefulness of copper filtration for ERCP procedures (Recommendation grade $\mathrm{C}$ ).

\section{RP shields}

The most radiosensitive organs (thyroid gland, breasts, gonads, and eyes) should be kept out of the main X-ray beam whenever possible, especially in oblique radiographic projections. The use of RP shields to decrease patient radiation exposure is not recommended in the general patient population (Recommendation grade $D$ ).

\section{Patient information about radiation risks}

It is recommended to provide information to the patient about radiation risks only in the case of ERCP repetition within 1 month or in cases of high doses as defined by a KAP > $300 \mathrm{~Gy} \cdot \mathrm{cm}^{2}$ (Recommendation grade $D$ ).

\section{RP in special cases}

Compared with adults, children are more sensitive to radiation exposure, especially at younger ages (Evidence level 1+). In children, there must be a strong clinical indication to for carrying out ERCP; this should be performed by experienced endoscopists only and RP measures similar to those used in adults should be strictly followed, including adjustment of collimation to the smaller size of children (Recommendation grade $B$ ). The most radiosensitive organs (thyroid gland, breasts, gonads, and eyes) should be protected with $R P$ shields and should be kept out from the main X-ray beam, especially in oblique radiographic projections (Recommendation grade D). Magnetic resonance cholangiopancreatography (MRCP) and endoscopic ultrasound (EUS) are accurate in the detection of common bile duct (CBD) stones (Evidence 1+). Therapeutic ERCP is relatively safe and effective during pregnancy when performed by experienced endoscopists with adapted techniques. Fluoroscopy requirements may be reduced by using specific ERCP techniques (Evidence level 3). A pregnancy test should be obtained before ERCP in women for whom there is doubt about pregnancy (Recommendation grade $D)$. ERCP in pregnant women should be performed only with a therapeutic purpose (Recommendation grade A); it is probably best performed by experienced ERCP endoscopists during the second trimester of pregnancy, strictly following recommendations to decrease patient radiation dose and with an RP apron wrapped around the patient's abdomen (Recommendation grade D).

Quality assurance

Legal requirements concerning the quality assurance of the equipment

Quality control of X-ray systems is mandatory and acceptance testing needs to be carried out before the first use of the equipment and thereafter on a regular basis (Recommendation grade $D$ ). 
Table 2 Standard definitions of technical terms.

\begin{tabular}{|c|c|c|c|}
\hline $\begin{array}{l}\text { Term [Reference for } \\
\text { official definition] }\end{array}$ & $\begin{array}{l}\text { Symbol used in } \\
\text { this Guideline }\end{array}$ & Unit & Definition \\
\hline Absorbed dose [4] & D & Gy & Amount of energy imparted by ionizing radiation to unit mass of absorbing material. \\
\hline Cumulative dose [5] & $C D$ & Gy & $\begin{array}{l}\text { Sum of air kerma from fluoroscopy and radiography from the beginning of the procedure } \\
\text { measured at a specified point on the X-ray beam axis (e. g., at the interventional reference } \\
\text { point). This point is representative of the position of the patient's skin. }\end{array}$ \\
\hline Tissue reactions & - & - & $\begin{array}{l}\text { Effects of radiation that are believed to have a threshold level below which no tissue } \\
\text { reactions are seen; the threshold is variable, depending on the nature and condition of the } \\
\text { exposed tissue. For doses in excess of the threshold, the severity of tissue reactions in- } \\
\text { creases with radiation dose. }\end{array}$ \\
\hline Dose reference level [6] & DRL & - & $\begin{array}{l}\text { Radiation dose levels determined for typical examinations for groups of "standard" } \\
\text { patients }(70-75 \mathrm{~kg}) \text { that are expected not to be exceeded for standard procedures when } \\
\text { good and normal practices are applied. }\end{array}$ \\
\hline Effective dose [7] & E & Sv & $\begin{array}{l}\text { Average of radiation doses received by the different organs or tissues, weighted for the } \\
\text { relative biological effectiveness of the types of ionizing radiation as well as for the sensi- } \\
\text { tivity of the organs or tissues. }\end{array}$ \\
\hline Entrance skin dose [8] & ESD & mGy & $\begin{array}{l}\text { Absorbed dose to skin or muscle measured at the point where it enters the patient; it } \\
\text { includes backscattered radiation (i. e. the radiation reflected back in the direction it came } \\
\text { from). }\end{array}$ \\
\hline Equivalent dose [9] & - & Sv & $\begin{array}{l}\text { Value obtained by multiplying the absorbed dose by a radiation weighting factor, to take } \\
\text { into account the degree of biological damage produced by a particular type of ionizing } \\
\text { radiation. }\end{array}$ \\
\hline Fluoroscopy time & FT & s & Total time of fluoroscopy use during an imaging or interventional procedure. \\
\hline Gray [7] & Gy & Gy & Energy absorption of 1 joule per $\mathrm{kg}$. \\
\hline Kerma [4] & K & Gy & $\begin{array}{l}\text { Ratio of the kinetic energies of all charged particles which are generated in a volume } \\
\text { element by indirectly ionizing radiation ( } y \text { rays or neutrons) to the mass of the volume } \\
\text { element }\end{array}$ \\
\hline Air kerma [4] & $\mathrm{K}_{\mathrm{air}}$ & Gy & Kerma in air. \\
\hline Kerma - area product [8] & KAP & $\mathrm{Gy} \cdot \mathrm{cm}^{2}$ & $\begin{array}{l}\text { Air kerma multiplied by the X-ray beam cross-sectional area at the point of measurement } \\
\text { (this can be displayed on the equipment as dose-area product or DAP). }\end{array}$ \\
\hline Scattered radiation & - & - & $\begin{array}{l}\text { Radiation arising from interactions of the primary beam with patient tissues or other } \\
\text { scattering medium (patient table or other). }\end{array}$ \\
\hline Stochastic effects & - & - & $\begin{array}{l}\text { Effects of radiation that are believed to happen without identifiable threshold. The } \\
\text { probability that they occur increases with the radiation dose and their severity has no } \\
\text { relationship to the radiation dose. Risk is cumulative with time. }\end{array}$ \\
\hline
\end{tabular}

Analysis of patient radiation dose values

Recorded KAP values should be used for the study of interendoscopist, intrahospital, and interhospital variations in patient radiation exposure and for comparison with the available regional and national DRLs (Recommendation Grade D).

\section{Radiological unit selection for ERCP}

The endoscopist and the medical physicist should be involved in the selection of the radiological system used for endoscopic examinations. They should determine in advance the desired radiological performance and RP specifications (Recommendation Grade D).

\section{Education and training}

\section{$\nabla$}

Education programs in RP are mandatory under European Directive and Member States' laws for physicians who use diagnostic Xray, including nonradiologists, to reduce radiation doses to patients while maintaining adequate image quality (Recommendation grade $D)$.

Various international bodies, including the World Health Organization, the European Commission (EC) and the European Union (EU) Council (Council Directive 97/43/Euratom) stress the importance of educating and training physicians, medical physicists, maintenance engineers, and other auxiliary personnel involved in medical radiation exposure, to reduce patient radiation doses while maintaining the desired level of image quality $[6,10$,
11]. EC guidelines recommend 30-50 hours of theoretical training (20 hours have been proposed by Vano et al. [12]) plus practical exercises and they detail a list of topics $[10,12]$; they also make recommendations for continuing education and training after qualification. These EC guidelines represent recommendations to the Member States. No evidence was found in the literature on how these educational programs should be carried out and on the number of cases required for an endoscopist to be proficient in RP during ERCP.

We therefore recommend in addition that credentialing of RP training programs be established by regulatory authorities at a national or a regional level, with the help of academic institutions, and scientific and/or professional societies.

\section{State of knowledge \\ $\nabla$}

\subsection{Tissue reactions and stochastic effects of radiation}

Radiation effects on tissues can be classified as tissue reactions and stochastic effects, as defined in Table 2. Examples of tissue reactions include cataract formation, infertility, skin injury, and hair loss. These have been documented in interventional radiologists and cardiologists [13] and in patients who have undergone interventional cardiology and radiology procedures. Stochastic effects are more delayed compared with tissue reactions (years to decades vs. hours to months); examples of stochastic effects include radiation-induced cancers and genetic defects [14]. 


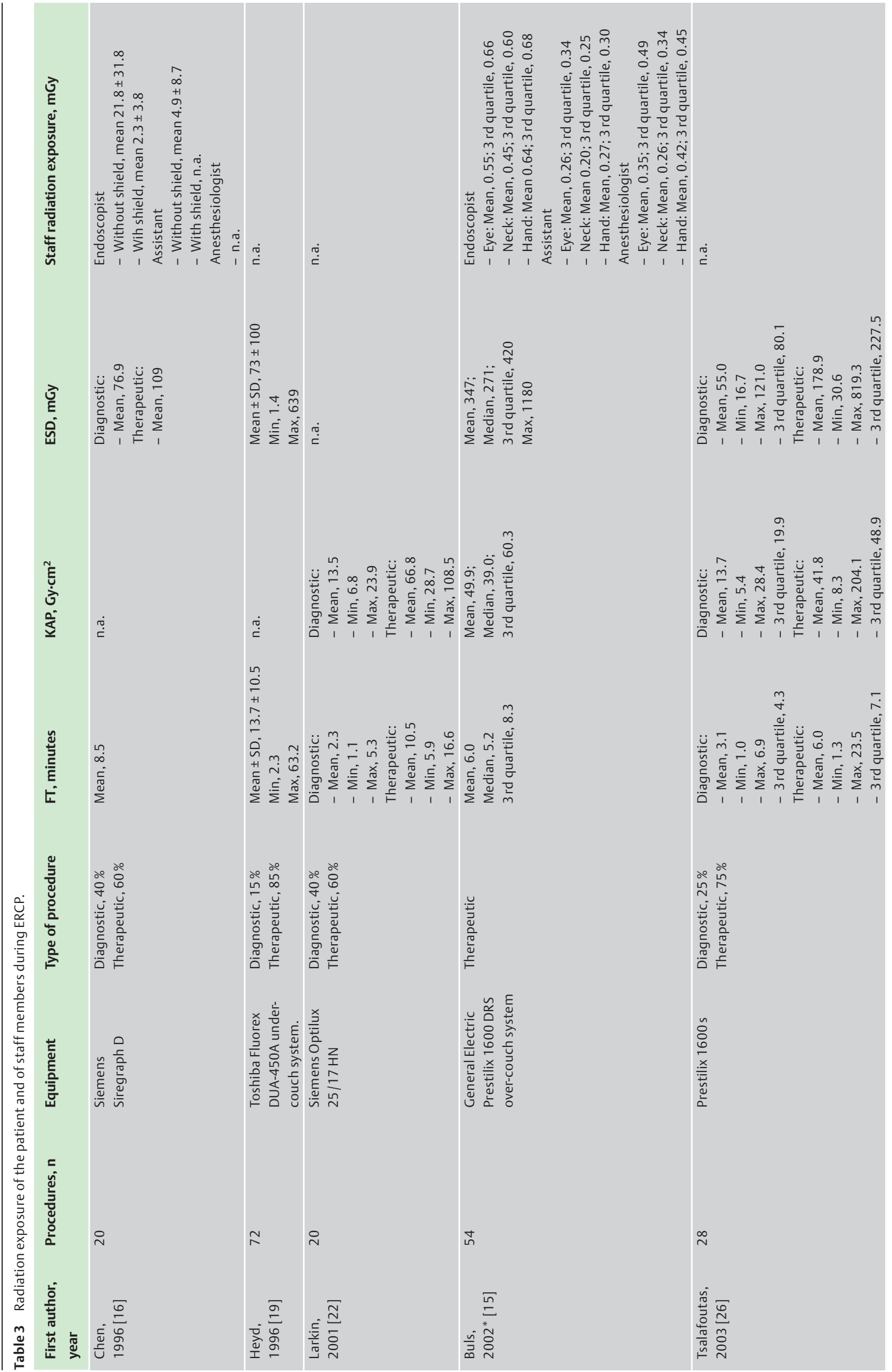




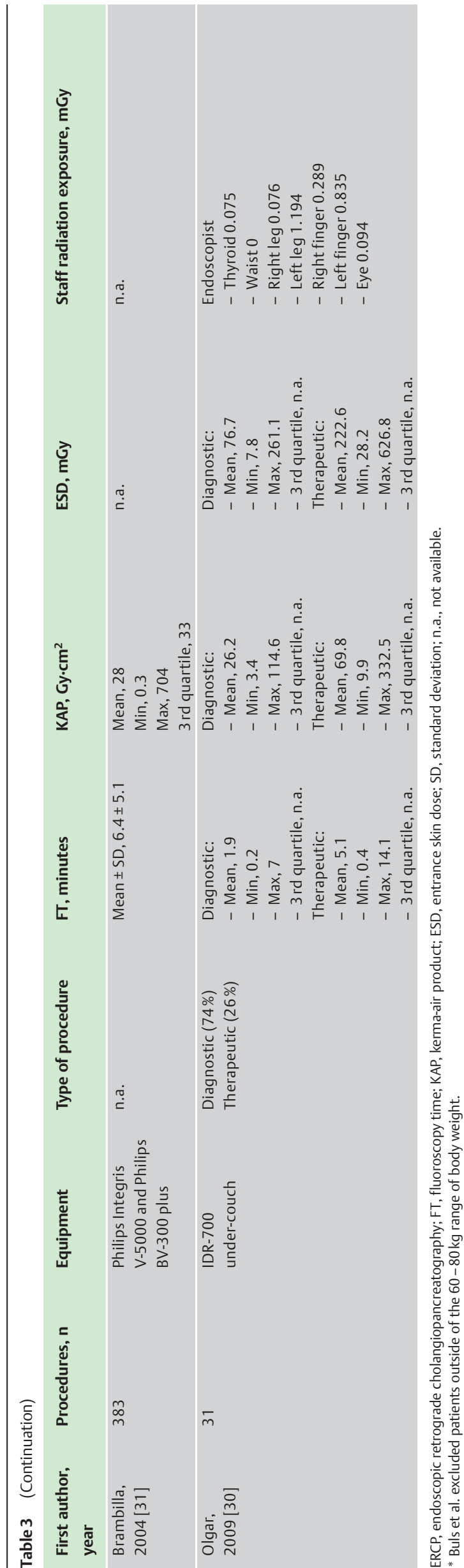

\subsection{Types of X-ray systems}

Systems that have the X-ray tube located above or under the patient table are described as "over-couch" or "under-couch" systems, respectively. Mobile X-ray units, also called "mobile C-arm units," are usually used under-couch. For ERCP, both over-couch and undercouch systems are used. The difference between over-couch and under-couch systems is more relevant to healthcare staff than to patients, as which area of a staff member's body receives most radiation exposure depends on which type of system is used. Staff radiation exposure may be significantly higher with mobile C-arm units and over-couch $X$-ray systems compared with stationary under-couch $X$-ray systems (Evidence level 2+).

Among 13 ERCP studies that were analyzed for the X-ray tube position, the distribution between the use of over-couch and undercouch systems was almost even [15-27]. Scattered radiation mostly affects the lower or the upper part of the bodies of staff with under-couch or over-couch systems, respectively. Radiation-induced cataract has been reported in interventional radiologists using over-couch X-ray systems without RP equipment [28]. Four studies were identified that reported radiation doses measured at the level of the endoscopist's eye: the lowest mean radiation doses were observed with under-couch systems while radiation doses were particularly high with an over-couch system that had no protective shield $[15,16,29,30]$. Regarding patient radiation doses with ERCP, no evidence was found about any possible impact of the position of the X-ray source or of patient position (prone vs. supine), although differences are likely to exist.

A single comparison of a stationary vs. a mobile X-ray unit (both under-couch) was found, that showed higher radiation doses with the mobile C-arm unit (with the stationary system, doses for the anesthesiologist and the endoscopist were $0.273 \mathrm{mGy} / \mathrm{h}$ and $0.013 \mathrm{mGy} / \mathrm{h}$, respectively; corresponding values for the mobile C-arm unit were $0.9 \mathrm{mGy} / \mathrm{h}$ and $1.04 \mathrm{mGy} / \mathrm{h}$, respectively) [21].

\subsection{Radiation doses during ERCP}

The mean entrance skin dose (ESD) during ERCP ranges between 55 and $347 \mathrm{mGy}$ in most studies, with values approximately three times higher for therapeutic compared with diagnostic ERCP. Mean values of kerma-area product (KAP) reported for diagnostic and therapeutic ERCP are in the range of 3-115 Gy $\cdot \mathrm{cm}^{2}$ and 8$333 \mathrm{~Gy} \cdot \mathrm{cm}^{2}$, respectively (Evidence level $2+$ ). Limited information regarding dose reference levels (DRLS) is available for ERCP. The United Kingdom (UK) and the Nordic RP authorities have proposed $K A P$ values of $20 \mathrm{~Gy} \cdot \mathrm{cm}^{2}$ and $50 \mathrm{~Gy} \cdot \mathrm{cm}^{2}$, respectively. For examinations different from ERCP, recording patient radiation doses at a national level was followed by a decrease in patient radiation exposure (Evidence level $2-$ ). We recommend reporting patient radiation doses in a national database (Recommendation grade $D$ ).

- Table 3 summarizes values of ESD and of KAP measured during ERCP with a variety of X-ray systems. The most important factors influencing patient radiation doses include the duration of fluoroscopic examination (fluoroscopy time, FT), the number of radiographs taken, patient body size, and exposure parameters (e.g., pulsed vs. continuous fluoroscopy) $[16,19,22,26]$. KAP and ESD values are higher for therapeutic compared with diagnostic ERCPs, mostly because of longer FT during therapeutic procedures.

DRLs are defined as the 3 rd quartile of KAP values measured in a large series of procedures for a particular radiological examination. According to good clinical practice, they should not be ex- 
ceeded for standard procedures (they represent a guide, not a limit). Member States of the EU were required to promote the establishment and the use of DRLs according to a Directive (97/43/ Euratom) that had to be implemented into national laws by Member States not later than May 2000 [6]. Although the establishment of DRLs would be very useful in view of the large range of KAP values reported during ERCP ( Table 3 ), little progress has been made so far. In Nordic European countries, the DRLs proposed for ERCP do not report separately on diagnostic and therapeutic procedures [32]; in the UK, DRLs have been established for "biliary drainage/intervention" based on data collected in approximately 40 examination rooms [33]; however "biliary drainage/intervention" was not clearly defined [34]. Every 5 years in the UK, a review of the National Patient Dose Database reports the doses of patient radiation exposure for several examinations. The latest review included data from approximately 25 $\%$ of UK hospitals; it showed that the mean patient radiation doses have progressively decreased over time, suggesting that some of the hospitals exceeding the DRLs have taken corrective actions [33].

Values proposed for DRLs in Nordic European countries and in the UK, together with those reported in Table 3, were used to propose DRLs for therapeutic ERCP during the development of the current Guideline. Few data were found; as an indication, the 3 rd quartile of KAP values reported for therapeutic ERCP in various studies ranged between 33.0 and $60.3 \mathrm{~Gy} \cdot \mathrm{cm}^{2}[15,26$, 31].

\section{Dosimetric aspects}

$\nabla$

\subsection{Staff monitoring}

The effective dose $(E)$ is best estimated by wearing two dosimeters: one at the neck, outside of the protective apron, and the other one under the protective apron, at waist level (Evidence level 1 -). Radiation doses to the extremities (hands, fingers, legs) are low during ERCP with appropriate RP shielding, compared with recommended radiation dose limits (Evidence level $2+$ ). For staff monitoring, the use of two dosimeters is recommended but a single dosimeter worn under the RP apron can provide a reasonable estimate of $E$ in most cases and may be more practical. If this single dosimeter is worn over the apron it can also provide a good estimation of eye lens doses. With appropriate shielding, monitoring of extremity radiation doses is not needed. When no shielding is available, a sample of test measurements should be obtained to decide whether or not moni- toring of extremity radiation doses is needed. (Recommendation grade C). An appropriate algorithm must be used to avoid overestimation or underestimation of E when only one dosimeter is used. With the forthcoming lowering of the recommended radiation dose limit for the eye lens to $2 \mathrm{mSv} /$ year, monitoring of radiation doses at the level of the eye lens will be needed with over-couch systems that do not have adequate RP shielding. (Recommendation grade $D$ ).

E provides a measure of the radiation damage caused by partial and whole body irradiation. Recommended radiation dose limits have been defined for persons with occupational exposure to Xrays ( $\bullet$ Table 4 ) [7]. Several review articles recommend the wearing of two dosimeters, one over and one under the RP apron, because this allows a better estimation of $E$ compared with a single dosimeter [35-38]. There are different algorithms for estimating $\mathrm{E}$, depending on the number and location of dosimeters that are worn and the use of RP aprons and thyroid collars [39]. Many national legal requirements clearly state how many, when, and where dosimeters should be worn, and how E should be estimated. No EU harmonization exists on this topic. E to endoscopists has been estimated to be $2-90 \mu \mathrm{Sv}$ per ERCP based on measurements using two dosimeters [23], and as 3-70 $\mu \mathrm{Sv}$ when one dosimeter was used $[16,23,30,40,41]$. Doses to endoscopy assistants are reported to be lower $[16,20,23]$. The annual price of dosimetry ranges from 30 to 150EUR per person, including the cost of dosimeter rental and of measurements.

Radiation doses at the level of extremities are approximately $30 \mu \mathrm{Sv}$ per ERCP (median values) [42]; these values are low enough to recommend no routine monitoring of extremity radiation doses. However, when no appropriate shielding is available and over-couch X-ray tubes are used, higher radiation doses have been reported (between 350 and $800 \mu \mathrm{Sv}$ per procedure) $[15,30,43]$. In such cases, monitoring of extremity radiation doses using ring or wrist dosimeters is indicated. When no RP shielding is available, it is recommended that test measurements be performed to determine the order of magnitude of extremity doses, for example by introducing a routine monitoring program for a few months using ring or wrist dosimeters. These measurements can be extrapolated to yearly doses and compared with the annual dose limits. Any need for continuous extremity dose monitoring can then be decided upon by the RP officer.

For the eye lens, the International Commission on Radiological Protection (ICRP) has proposed lowering the recommended radiation dose limits of $\mathrm{E}$ from $150 \mathrm{mSv}$ to $20 \mathrm{mSv}$ averaged over 5 years, with no single year exceeding $50 \mathrm{mSv}[8,30]$. This proposal

\begin{tabular}{|c|c|c|}
\hline \multirow[t]{2}{*}{ Type of limit } & \multicolumn{2}{|l|}{ Annual limit, mSv } \\
\hline & Occupational exposure & General public \\
\hline Effective dose & 20 , averaged over defined periods of 5 years ${ }^{1}$ & 1 \\
\hline \multicolumn{3}{|c|}{ Annual equivalent dose in: } \\
\hline Lens of the eye ${ }^{2}$ & 20 & 15 \\
\hline Skin 3,4 & 500 & 50 \\
\hline Extremities & 500 & \\
\hline Pregnant woman & 2 (measured at the abdomen surface for the $w$ & \\
\hline Fetus $^{5}$ & 1 & \\
\hline $\begin{array}{l}1 \text { With the further provis } \\
\text { occupational exposure } \\
2 \text { This radiation dose lim } \\
\text { has not yet been imple } \\
{ }^{3} \text { The limitation on effec } \\
{ }^{4} \text { Averaged over } 1 \mathrm{~cm}^{2} \text { ar } \\
{ }^{5} \text { Radiation dose limit in }\end{array}$ & $\begin{array}{l}\text { ective dose should not exceed } 50 \text { mSv in any single ye } \\
\text { omen. } \\
\text { geen recommended by an International Commission o } \\
\text { pean regulations. } \\
\text { des sufficient protection for the skin against stochasti } \\
\text { rdless of the area exposed. } \\
\text { lations. }\end{array}$ & $\begin{array}{l}\text { s apply to the } \\
\text { sk Group but it }\end{array}$ \\
\hline
\end{tabular}

Table 4 Recommended radiation dose limits for workers with occupational exposure [7]. 
will be adopted by the Basic Safety Standards of the EC, so that monitoring of eye lens doses will be required when no shielding is present in over-couch systems.

\subsection{Patient dose monitoring}

Among the easily available metrics for radiation exposure, KAP is the best for monitoring patient radiation dose (Evidence level $2++$ ). KAP should be monitored, and its cumulative value should be recorded in the patient file for every ERCP, by either the radiology technician or the attending endoscopist (Recommendation grade $B$ ).

According to the Council of Europe Directive 97/43/Euratom (Article 8 ) $[6,11]$, patient radiation doses must be estimated. The Directive has been implemented in national legislations, as shown in France for example [44]. According to the Directive, a record of dosimetry data should be maintained for each patient, including for procedures performed with a mobile C-arm unit. Other existing guidelines recommend dose recording only when ESD exceeds 1 - 2 Gy for a procedure, with ERCP not listed as a procedure with radiation-associated risk in Food and Drug Administration (FDA) recommendations [45-47].

Although the link between KAP and patient $\mathrm{E}$ is indirect, KAP is one of the best available parameters for estimating ESD and E to the patient (and to the fetus in the case of pregnancy) [24,30,48, 49]. KAP is generally measured using a KAP-meter, i.e., a large area ionization chamber located immediately at the exit of the $\mathrm{X}$-ray tube and collimation device. The cost of a KAP meter may vary widely depending on specifications; a reference price is 3000 EUR. KAP values can also be calculated using an internal algorithm that takes into account the X-ray generator settings combined with collimator data. FT has been investigated as an alternative measure for estimating KAP and/or patient E; some studies reported a good correlation [22, 26,30,48], but other studies reported poor correlation [31, 32]. In compliance with FDA requirements [50], up-to-date fluoroscopy equipment can provide an estimate of the cumulative dose [51]. This measure correlates better with ESD compared with KAP values [52]; however it is not yet widely available.

\subsection{Medical physicist availability}

Endoscopists should have access to the support of a medical physicist to assess radiation doses and to optimize procedures (Recommendation grade $D$ ).

There is a consensus in the literature, reflected in the Council Directive 97 /43 / Euratom (which is binding on EU Member States), about the requirement for involving a medical physicist [11]. His/ her responsibilities would include quality control of the radiological suites, patient radiation dose monitoring, optimization of the compromise between acceptable image quality and lowest possible radiation dose to patients, and specific procedures to apply when a pregnant patient is involved $[37,53,54]$. Collaborative training programs involving the endoscopists, the radiation safety officer, and the medical physicist may also be useful.

\section{RP measures for staff}

$\nabla$

\subsection{Personal RP measures}

\subsubsection{Staff positioning}

Radiation dose is inversely proportional to the square of the distance from the X-ray source (Evidence level $1++$ ). Radiation exposure of staff members is significant; highest radiation doses are usually measured at the locations of the endoscopist and of the person mon-

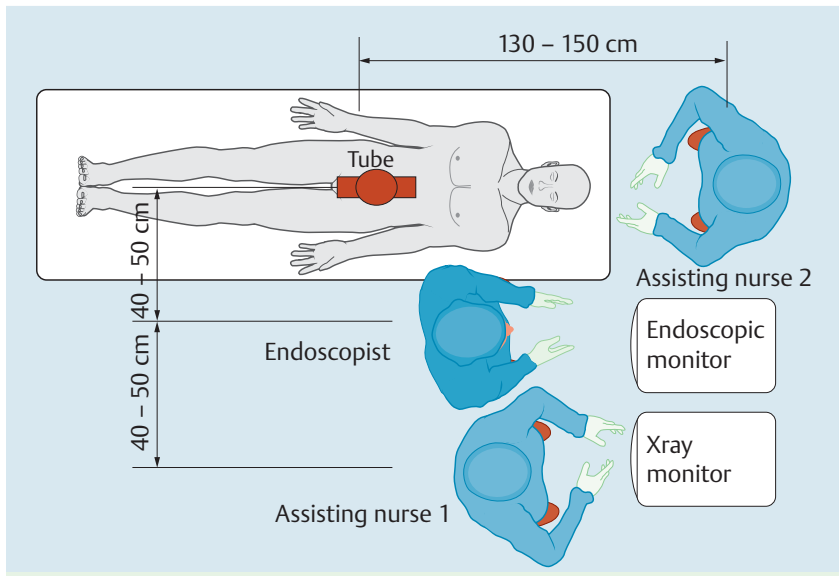

Fig. 1 Typical patient and staff positioning during endoscopic retrograde cholangiopancreatography (ERCP).

itoring patient sedation (Evidence level 2-). Staff should be positioned as far as possible from the X-ray tube and from the patient, the source of scattered radiation (Recommendation grade $A$ ). We recommend positioning RP shields to protect all staff members, including the endoscopist and the person monitoring patient sedation (Recommendation grade $D$ ).

Staff radiation exposure strongly depends on staff positioning during ERCP ( Fig.1). Because radiation doses decrease with the distance from the X-ray source and the endoscopy assistant is partially shielded by the endoscopist, the highest radiation doses are measured at the locations of the endoscopist and of the person monitoring patient sedation ( $\bullet$ Table 3 ) [15,21].

\subsubsection{Protective aprons and collars}

$R P$ aprons with lead-equivalent thickness $\geq 0.25 \mathrm{~mm}$ effectively reduce radiation exposure. Musculoskeletal complaints are frequent amongst endoscopists performing ERCP and may be increased by $R P$ aprons. Radiation exposure of the thyroid gland during ERCP may be significant, in particular when working with unshielded over-couch systems (Evidence level $2+$ ). All persons in the procedure room (except the patient and people in the area behind a stationary $R P$ shield if available) should wear a wrap-around (not front-only) $R P$ apron and an RP collar with lead-equivalent thickness $\geq 0.25 \mathrm{~mm}$ when X-rays are used (Recommendation grade C). An RP apron with a collar attached to it may encourage the use of thyroid shields. RP aprons should be hung vertically, to prevent cracks, in a place that can be reached under the protection of an RP shield (e.g., behind a stationary RP shield close to the entrance door or outside the endoscopy room). Moreover, they should be tested annually for defects (Recommendation grade $D$ ).

RP aprons of $0.25 \mathrm{~mm}$ lead-equivalent thickness attenuate $\geq 90 \%$ of scattered X-rays that strike them $[40,55,56]$. In a small experimental study based on an FT of 20 min per ERCP and standard E limits, it was estimated that, with regard to RP, fewer than one ERCP per month was permissible if no protective apron was used [40]. Radiation doses to the thyroid gland during ERCP may be significant particularly with unshielded over-couch systems (median of $0.3 \mathrm{mGy}$ per ERCP) [15]. Thyroid collars are recommended for staff members likely to receive monthly collar radiation monitor readings $>4 \mathrm{mGy}$ [57].

A majority of endoscopists performing ERCP have musculoskeletal complaints, back and neck pain being the most frequent [58]. Furthermore, musculoskeletal injuries are more frequent 
amongst physicians who wear RP aprons compared with those who do not, and in those who have been practicing ERCP longer [58 -61]. RP aprons are available in various shapes (front-protecting only, double-sided, two-piece, one-piece) and materials. A lightweight model, well-fitting, and reaching down to the knees should be chosen. Two-piece RP aprons or one-piece RP aprons with a waist belt may distribute the load more evenly across the spine and pelvis [62]. Wrap-around RP aprons with $0.25 \mathrm{~mm}$ lead-equivalent thickness provide a $0.5 \mathrm{~mm}$ lead equivalence in the front part of the body. In most currently available RP aprons, lead has been replaced with lightweight lead composite or leadfree material (barium, tungsten, tin, and antimony) that provide the same protection as lead at approximately $30 \%$ of the weight [63].

\subsubsection{RP gloves and glasses}

$R P$ gloves are uncomfortable for ERCP and provide limited X-ray attenuation (Evidence level $2++$ ); they are not recommended during ERCP (Recommendation grade B). Optimal RP of the eyes during fluoroscopy depends heavily upon location of the $X$-ray source and on RP shielding (Evidence level $2++$ ). If an over-couch system is used with no $R P$ shield, all persons in the procedure room except the patient should wear RP glasses with side panels or an RP facemask (Recommendation B).

RP gloves are expensive, have a short lifespan, attenuate X-rays by only $15 \%-30 \%$, and add scattered X-rays within the glove [64]. The best practice is to keep the hands out of the X-ray beam rather than wearing RP gloves.

The lens of the eye is one of the most radiosensitive human tissues and lens exposure to ionizing radiation can cause cataract [13]. In a controlled study that included 209 persons, the relative risk of posterior subcapsular lens opacities in interventional cardiologists compared with unexposed controls was 3.2 (38\% vs. $12 \% ; P=0.005)$ [29]. Most commercially available RP glasses have lenses of $\geq 0.5 \mathrm{~mm}$ lead-equivalent thickness that effectively attenuate radiation transmission to the eyes; they must have side panels to block scattered radiation while the wearer looks at the display monitor during fluoroscopy. Such RP glasses may be heavy and uncomfortable. Photochromic lenses are lighter but they transmit $50 \%$ of radiation if the angle of incidence is within $60^{\circ}$ of the perpendicular to the lens [65]. RP of the eyes can also be achieved with an RP facemask or a mobile barrier that can prevent scattered radiation from reaching the head of the staff member and avoid the discomfort associated with RP glasses [66]. RP glasses are recommended only when over-couch systems are used.

\subsubsection{RP shielding above and/or below the table}

Staff radiation exposure may be decreased by $\geq 90 \%$ by using $R P$ shields located between the X-ray tube/patient and the staff. Mobile $C$-arm units cause more radiation exposure to staff than stationary $X$-ray units, in part because of the frequent absence of RP shielding attached to these systems (Evidence level $2+$ ). Shields of $\geq 0.5 \mathrm{~mm}$ lead-equivalent thickness should be positioned between the X-ray tube/patient and the staff, including when mobile C-arm units are used (Recommendation grade $\mathrm{C}$ ).

Although RP aprons are effective, X-ray doses to the unshielded parts of the body may be significant during ERCP. For example, radiation doses at the level of operators' legs were found to be as high as $2.6 \mathrm{mSv}$ per procedure when no shield was used [67]. Mobile C-arm units provide more radiation exposure to staff members than stationary X-ray units mainly because these types of systems do not usually have a shield attached [21]. Radiation exposure to the staff may be decreased by $90 \%$ using RP shields; depending on their location, RP shields protect the endoscopist and/or the person monitoring patient sedation [16, 19,21]. The size of the protected zone increases when the shielding is moved closer to the X-ray source [68]. Shields should be located above or below the patient table for over-couch or under-couch systems, respectively. A vertical shield suspended from the patient table is a standard accessory for under-couch stationary X-ray systems. If no RP shield is attached or with other types of X-ray systems (Carm units/over-couch systems), a free-standing vertical shield should be added, either hanging from the ceiling or movable on the floor, between the patient and the endoscopist, and a second one should be placed to protect the person monitoring patient sedation ( Fig.1). Approximate costs of articulated window lead glass RP shields, stand-alone whole-body mobile RP shields, and vertical RP shields attached to the patient table are 5000, 3000, and 1000 EUR, respectively ( $\bullet$ Fig. 2 and $\bullet$ Fig. 3). Shields may also decrease the risk of inadvertent radiation exposure to people entering the endoscopy room without adequate RP.

\subsection{Signs and warnings}

Visible alarms (typically, light flashing when fluoroscopy is in progress, and posters that ask patients to inform about possible pregnancy) should be present, close to each door of an endoscopy room where there is a stationary $X$-ray unit (Recommendation $D$ ).

There are no trials available regarding this issue but radiationwarning lights inside and outside the examination room are recommended; they must operate automatically [68]. Regulations

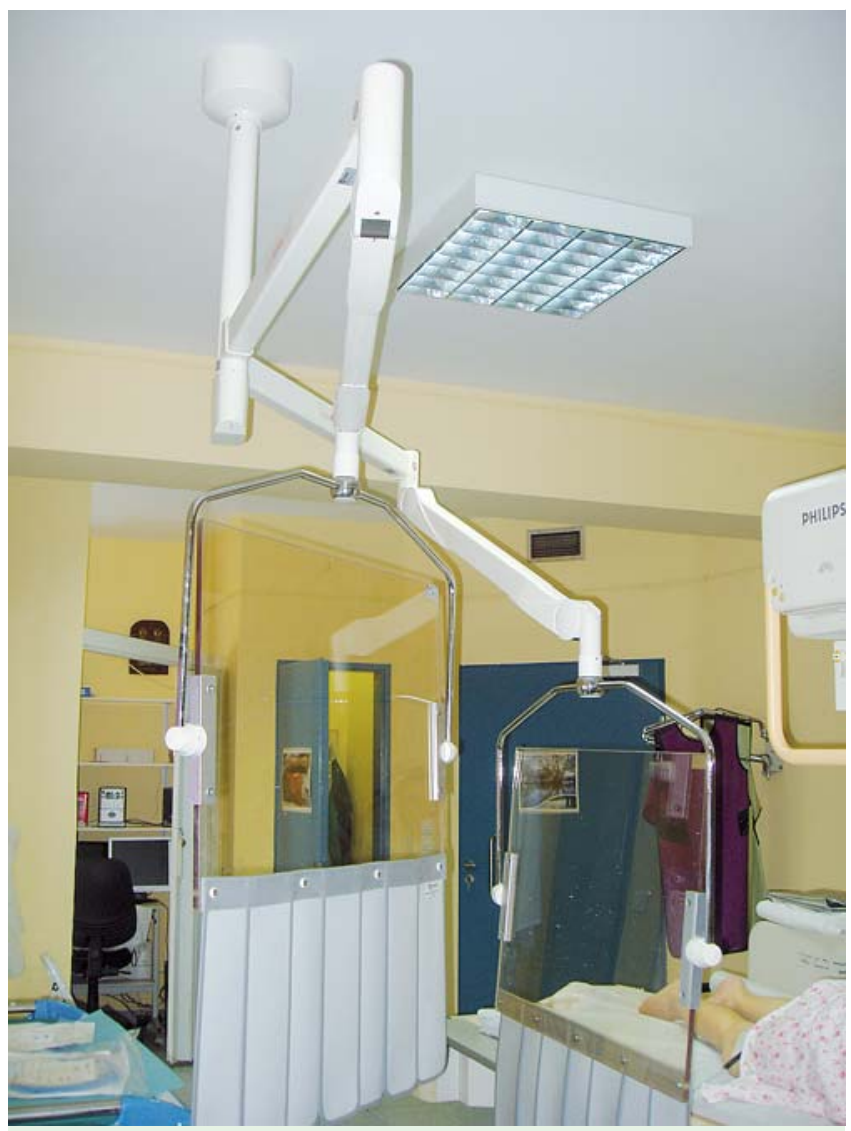

Fig. 2 Mobile radiation shields with drapes at the bottom, suspended from ceiling. 


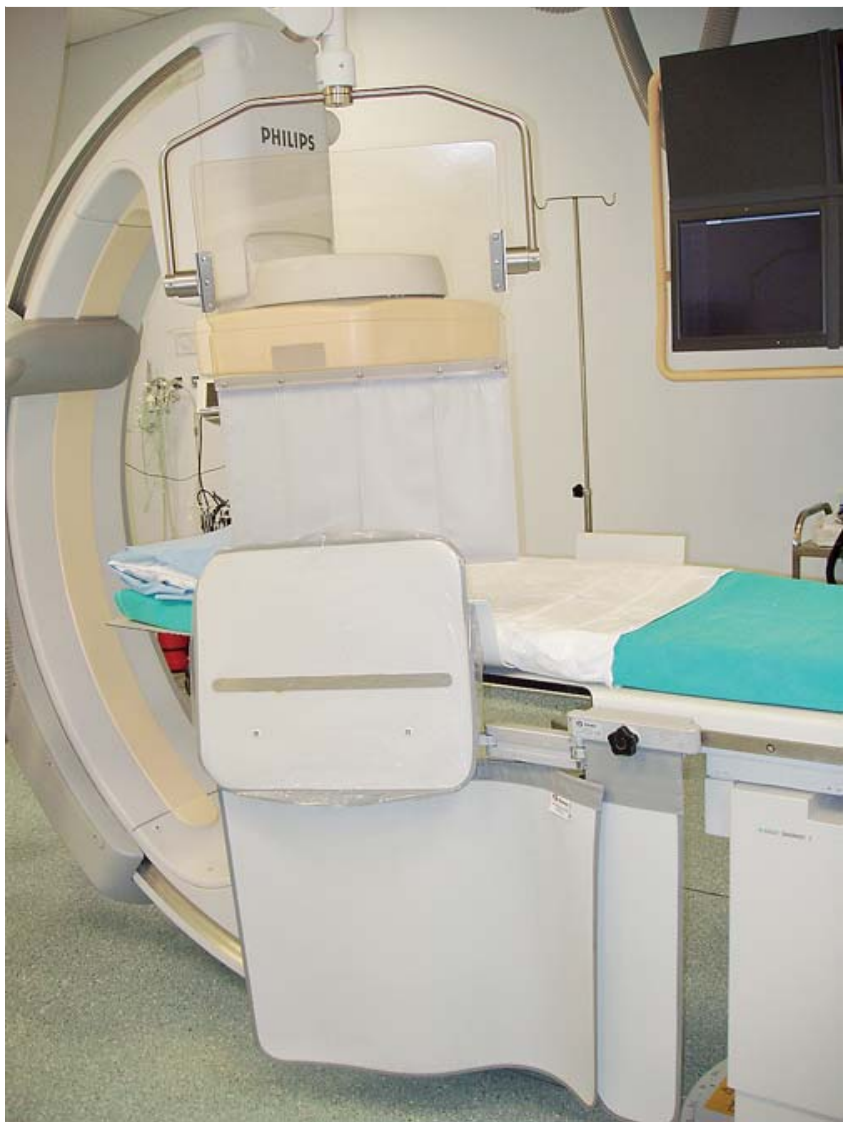

Fig.3 Under-couch X-ray system with protective radiation shields placed under and over the table, to protect the endoscopist from radiation that originates from the X-ray tube and from the patient (scattered radiation), respectively.

about warnings that are activated when X-rays are being delivered vary considerably between EU countries (e.g., warning lights outside of the room are legally required in Greece). Doors leading into the X-ray room must have signs that indicate the presence of the X-ray unit. Notices that ask patients to inform about possible pregnancy should be posted at the reception area [69].

\subsection{RP shielding of examination rooms}

Appropriate structural shielding is required for stationary $X$-ray units and should be considered with some mobile C-arm units. Room shielding requirements should be calculated by a medical physicist.

In most countries, the law requires that appropriate structural RP shielding is in place in the walls, doors, ceiling, and floor of a room housing a stationary X-ray unit. It also recommends that structural RP shielding is considered for procedure rooms where mobile C-arm units are routinely used [70]. This is intended to reduce radiation exposure of workers and the general population to a level lower than the established limits. Recommendations are available for how room RP shielding should be put in place; most recent recommendations are more accurate and allow reduction of shielding costs [71-73]. Room RP shielding should be designed by a medical physicist to ensure that the required degree of RP is achieved [73]. Stationary X-ray systems must provide a control booth with a viewing window that must have RP properties such that no operator is occupationally exposed to radiation doses higher than recommended E limits.

\subsection{Special case: pregnant staff}

A female employee in a working environment with risk of radiation exposure has the right to know about potential radiation hazards to the unborn child before she becomes pregnant or decides to formally declare her pregnancy. Furthermore, in some countries legislation requires that women immediately declare their pregnancy. The employer of a declared pregnant worker must evaluate the work situation and ensure that the radiation dose to the conceptus is kept below the maximum permissible level during the remaining gestation period. A method has been developed to anticipate the radiation dose to the fetus and to determine the maximum workload allowed for a pregnant employee; this methodology may be used for implementing an RP program designed for pregnant staff working in ERCP rooms [74].

\section{RP measures for the patient \\ $\nabla$}

\subsection{Patient position}

Radiation dose is inversely proportional to the square of the distance from the X-ray source (Evidence level $1++$ ). Therefore, the patient should be positioned as far as possible from the X-ray tube (i. e., close to the $X$-ray detector) (Recommendation grade $A)$.

\subsection{Fluoroscopy parameters}

Measures that decrease patient radiation exposure include: the use of pulsed rather than continuous fluoroscopy (Evidence level 2-), and of time-limited fluoroscopy (Evidence level 1-); avoidance of taking radiographs; increasing the tube voltage (this may decrease image quality) (Evidence level $2+$ ); and collimating $X$-rays to a small field of view (this increases image quality) (Evidence level $1++$ ). It is recommended to use pulsed fluoroscopy with the lowest possible pulse rate, rather than continuous fluoroscopy; to store when possible the "last image hold" as an alternative to taking a radiograph; to collimate the X-ray beam to the smallest practical size; to increase tube voltage as far as possible without compromising image quality; and to use magnification modes only if necessary. The use of timelimited fluoroscopy may also be considered if this is not too impractical (Recommendation grade $\mathrm{C}$ ).

The most important measures to reduce radiation doses and to comply with the ALARA principles (ALARA stands for "As Low As Reasonably Achievable") are listed in Table 5. The simplest measures to decrease patient as well as staff radiation exposure consist of using fluoroscopy for less time and not taking any radiographs. FT is inversely correlated with endoscopist experience $[27,75]$, with a reported decrease in FT of $20 \%$ per 10 years of experience [75]. Pulsed fluoroscopy is effective for reducing radiation exposure in interventional procedures (a rate of 7.5 pulses per second may reduce radiation exposure by up to $70 \%-$ $80 \%$ ) $[76,77]$. The use of pulsed fluoroscopy was shown not to significantly affect image quality for examinations different from ERCP [78]; during ERCP, we feel that it may be used most of the time, with higher pulse rates or continuous modes used for delicate phases of the procedure. Taking radiographs accounts for $10 \%-30 \%$ of the total radiation dose during ERCP $[16,19,22$, $26]$. This extra radiation can be avoided by using when possible the "last image hold" feature of fluoroscopy systems in place of taking true radiographs. As an example, in one study that used a digital radiographic unit and an additional copper filter, KAP for one radiograph was equivalent to $2-4 \mathrm{~s}$ of fluoroscopy [15]. Selecting the lowest reasonable image quality also allows reduction of radiation doses (most of the modern mobile and stationary $\mathrm{X}$ - 


\begin{tabular}{l}
\hline Table 5 Recommendations for reducing patient radiation dose during ERCP. \\
- Position the patient as far as possible from the X-ray tube \\
- Limit fluoroscopy time \\
- Use pulsed fluoroscopy at a rate as low as possible \\
- Select the lowest reasonable image quality in fluoroscopy mode \\
- Collimate the X-ray beam to the smallest practical size \\
- Avoid unnecessary magnification \\
- Use "last image hold" rather than taking radiographs \\
- Increase tube voltage (kV) as much as allowed by image quality \\
- Experienced endoscopist for performing more complex cases
\end{tabular}

ERCP. endoscopic retrograde cholangiopancreatography

ray systems provide the possibility of selecting different image qualities in fluoroscopy mode).

Collimation of the X-ray beam also decreases patient and staff radiation exposure, in proportion to the image field area, and it improves image quality by reducing the scattered radiation that reaches the X-ray detector [79]. On the other hand, magnification of the X-ray image requires higher X-ray doses. As an example, in a ERCP study, air kerma $\left(\mathrm{K}_{\mathrm{air}}\right)$ was increased by a factor of approximately 4 by switching the field of view from $38 \mathrm{~cm}$ to 15 $\mathrm{cm}$ (a magnification factor of 2.5) [15]. Nonetheless, as the X-ray beam reaches a smaller area, the total energy imparted to the patient is grossly similar to that observed at low magnification with a larger area. Increasing tube voltage is another means of decreasing patient radiation exposure (by approximately $20 \%$ for an increase in tube voltage of $20 \mathrm{kV}$ ) but this may decrease image quality and it increases scattered radiation to staff members, although the latter has little clinical relevance [15, 16,19,80]. A value of $80-90 \mathrm{kV}$ is usually recommended. Recording of radiation doses seems to induce radiation awareness, which eventually leads to shorter FT and reduced radiation doses [81]. An RCT showed that limiting the use of fluoroscopy to 3-s periods allowed a significant decrease in FT [41]; however, the difference was significant in multivariate but not in univariate analysis and the consensus of the endoscopists participating in that RCT was that using fluoroscopy with a time limit of $3 \mathrm{~s}$ was cumbersome.

\subsection{Copper filtration}

A reduction in patient radiation dose of approximately $50 \%$, with reduction in image quality, can be achieved by inserting a copper filter in the X-ray beam (Evidence level 1-). We recommend testing the usefulness of copper filtration for ERCP procedures (Recommendation grade $\mathrm{C})$.

Copper filters (0.1-0.5 mm thick) are installed in most modern fluoroscopy units to reduce patient radiation exposure. As the copper filters are removable, endoscopists can assess whether image quality is adequate for ERCP. Such filters can also be taped onto older X-ray units. In a study that was performed in phantoms during various human cardiology interventions, the insertion of a $0.35 \mathrm{~mm}$ thick copper filter in the X-ray beam reduced the ESD by a mean of $58 \%$ with insignificant detriment to the image quality as evaluated by unblinded evaluators [82]. Data on radiation dose reduction and absence of significant alteration in image quality were confirmed in an RCT of barium enema examinations where evaluators were blinded to the patient allocation group [83]. A potential drawback of this method is an increased load on the X-ray tube, which can create overheating, but overheating due to copper filters is not problematic with modern Xray units.

\subsection{RP shields}

The most radiosensitive organs (thyroid gland, breasts, gonads and eyes) should be kept out of the main X-ray beam whenever possible, particularly in oblique radiographic projections. The use of $R P$ shields to decrease patient radiation exposure is not recommended in the general patient population (Recommendation grade D).

No original study that investigated this topic was found in the literature; special patient populations (i.e., children and pregnant women) are dealt with below.

\subsection{Patient information about radiation risks}

It is recommended to provide information to the patient about radiation risks only in the case of ERCP repetition within 1 month or in cases of high doses as defined by a KAP > $300 \mathrm{~Gy} \cdot \mathrm{cm}^{2}$ (Recommendation grade $D$ ).

No original study on this topic was found in the field of digestive endoscopy; general recommendations from various bodies (e.g., the ICRP) are available for interventional radiology [46]. In this field, patient counseling is recommended if ESD reaches or exceeds 2 to 3 Gy $[46,84]$. ESD values reported during ERCP are below $2 \mathrm{~Gy}[84,85]$, and there are no reports of radiation-induced tissue reactions following ERCP [86]. Therefore, conditions requiring patient counseling are likely exceptional, limited to procedures lasting for hours with frequent fluoroscopy use.

\subsection{RP in special cases}

\subsubsection{Pediatric patients}

Compared with adults, children are more sensitive to radiation exposure, especially at younger ages (Evidence level 1+). In children, there must be a strong clinical indication for carrying out ERCP; this should be performed by experienced endoscopists only and RP measures similar to those used in adults should be strictly followed, including adjustment of collimation to the smaller size of children (Recommendation grade $B$ ). The most radiosensitive organs (thyroid gland, breasts, gonads, and eyes) should be protected with $R P$ shields and should be kept out from the main X-ray beam, especially in oblique radiographic projections (Recommendation grade D).

In children, the sensitivity to cancer induction by radiation is considered to be higher than in adults by a factor of three to five. Follow-up studies after diagnostic X-ray examinations in children showed that cancer risks were correlated with radiation doses and were greatest for children irradiated early in life; risks for solid tumors persisted at least until the age of 50 years [14]. Because of the smaller size of children compared with adults, radiosensitive organs are closer together, so it could be difficult to position them outside of the X-ray beam. For all these reasons, ALARA concepts should be even more strictly followed in children [87].

8.6.2. Women of childbearing age, and pregnant patients Magnetic resonance cholangiopancreatography (MRCP) and endoscopic ultrasound (EUS) are accurate in the detection of common bile duct (CBD) stones (Evidence 1+). Therapeutic ERCP is relatively safe and effective during pregnancy when performed by experienced endoscopists with adapted techniques. Fluoroscopy requirements may be reduced by using specific ERCP techniques (Evidence level 3). A pregnancy test should be obtained before ERCP in women for whom there is doubt about pregnancy (Recommendation grade $D$ ). ERCP in pregnant women should be performed only with a therapeutic purpose (Recommendation grade A); it is probably best performed by experienced ERCP endoscopists during the second trimester of pregnancy, strictly following recommendations to de- 
crease patient radiation dose and with an $R P$ apron wrapped around the patient's abdomen (Recommendation grade $D$ ).

All women with childbearing potential should be thoroughly investigated about their reproductive status before ERCP. If any doubt exists, a pregnancy test should be obtained before performing ERCP. Cholelithiasis is the most frequent symptomatic biliary disease during pregnancy. If CBD stones are suspected, MRCP and EUS are accurate diagnostic tools that are devoid of radiation risks $[88,89]$. ERCP is the standard of care for treating choledocholithiasis during pregnancy: several case series are summarized in $\odot$ Appendix e3 (available online; [e90 - e96,e97, e98-e100,e101]), with most of them reporting no increase in the incidence of abnormal babies, preterm deliveries (less than $5 \%$ ) or abortion. On the other hand, surgical treatment of choledocholithiasis during the first trimester has historically been associated with a high abortion rate ( $12 \%-60 \%)$, but more recent case series suggest that laparoscopic cholecystectomy is safe during pregnancy [e102,e103,]. Although ERCP seems to be reasonably safe throughout the whole gestational period [e101], nonurgent ERCP is probably best performed during the second trimester because the fetus is more susceptible during organogenesis in the first trimester and the path of the X-ray beam is in the proximity of the unborn child during the third trimester.

The risk to the fetus for tissue reactions appears to have a threshold of $10 \mathrm{mGy}$ [e104]. For stochastic effects no threshold radiation dose is assumed. Therefore, the probability of a radiation-induced cancer can be reduced by keeping radiation exposure as low as possible. Shielding the fetus by placing a RP apron between the X-ray tube and the abdomen of the pregnant woman is recommended during fluoroscopy [e105, e106,]. Therefore, it is particularly important to determine whether the X-ray source is located below or above the patient (placing a protective apron under the woman's abdomen would be detrimental with overcouch systems). Only experienced ERCP endoscopists should perform these procedures as FT decreases with endoscopist experience [75]. Specific cannulation techniques have been used to bring about little or no radiation exposure to pregnant patients, including wire-guided cannulation and biliary access confirmation by bile aspiration [e97,e107]. Without fluoroscopy, complete CBD stone removal cannot be thoroughly checked (except by intraductal ultrasonography, and use of the latter is usually impractical) [e108]. In our opinion, the risks of recurrent cholangitis and of requirement for a second procedure probably outweigh the risk of short periods of fluoroscopy.

\section{Quality assurance}

v

\subsection{Legal requirements concerning the quality assur-} ance of the equipment

Quality control of X-ray systems is mandatory and acceptance testing needs to be carried out before the first use of the equipment and thereafter on a regular basis (Recommendation grade $D$ ).

In a national survey, ratios between the maximum and the minimum ESD values for various fluoroscopy units were in the range of 3 to 4 [e109]. This suggests that commissioning of the fluoroscopy units should be performed in the framework of the acceptance testing of X-ray systems before their first use with a patient. Annual stability testing of the fluoroscopy units is generally adopted, and the following parameters are evaluated during these tests: beam quality, beam collimation, equivalence between indicated and measured KAP, maximum $\mathrm{E}$ rate, and image quality parameters. The holder of the installation is responsible for the implementation of quality control [e110, e111].

\subsection{Analysis of patient radiation dose values}

Recorded KAP values should be used for the study of interendoscopist, intrahospital and interhospital variations in patient radiation exposure and for comparison with the available regional and national DRLs (Recommendation Grade D).

The mean KAP value from a representative sample of adult patients may be used as a measure of the typical dose from ERCPs performed by a particular endoscopist. We recommend comparing this value with corresponding mean KAP values of other endoscopists and with available regional or national DRLs, in order to ensure comparable dose levels between endoscopists and centers.

\subsection{Radiological unit selection for ERCP}

The endoscopist and the medical physicist should be involved in the selection of the radiological system used for endoscopic examinations. They should determine in advance the desired radiological performance and RP specifications (Recommendation Grade D). In choosing an X-ray system, the availability of experienced technical personnel in a given center should also be taken into consideration, so that prompt technical service is assured in the event of technical problems. At the time of installation, equipment performance evaluations should be conducted in order to ensure that the purchase specifications meet regulatory requirements. The records of the acceptance testing should be retained throughout the lifetime of the equipment for comparison with monitoring results in order to assess continued acceptability of performance [e112].

\section{Use of the guideline}

\section{$\nabla$}

The aim of this guideline is to provide caregivers with a comprehensive framework on how to use X-ray systems in a clinical setting. ESGE guidelines represent a consensus of best practice based on the available evidence at the time of preparation. They might not apply in all situations and should be interpreted in the light of specific clinical situations and resource availability. Further controlled clinical studies may be needed to clarify aspects of these statements, and revision may be necessary as new data appear. Clinical considerations may justify a course of action at variance to these recommendations. ESGE guidelines are intended to be an educational device to provide information that may assist endoscopists in providing care to patients. They are not rules and should not be construed as establishing a legal standard of care or as encouraging, advocating, requiring, or discouraging any particular treatment.

Competing interest: The authors declare no conflict of interest.

\section{Institutions}

${ }^{1}$ Service of Gastroenterology and Hepatology, Geneva University Hospitals, Geneva, Switzerland

${ }^{2}$ Service of Gastroenterology and Hepatology, Hospital S. Juan Dios del Aljarafe, Seville, Spain

${ }^{3}$ Institute of Radiation Physics, University Hospital Center of Lausanne, Switzerland

${ }^{4}$ Greek Atomic Energy Commission (GAEC), Agia Paraskevi, Athens, Greece ${ }^{5}$ Institut de Radioprotection et de Sûreté Nucléaire (IRSN), Fontenay-auxRoses, France 
${ }^{6}$ Department of Medical Physics, Faculty of Medicine, University of Crete, Iraklion, Crete, Greece

Department of Gastroenterology, University of Crete, Iraklion, Crete, Greece

${ }^{8}$ Departments of Gastroenterology, Konstantopoulio-Agia Olga Hospital, Athens, Greece

${ }^{9}$ Belgian Nuclear Research Centre (SCK-CEN), Mol, Belgium

${ }^{10}$ Medical Physics Department, Konstantopoulio-Agia Olga Hospital, Athens, Greece

\section{Acknowledgments}

$\nabla$

The authors thank Dr Renato Padovani and Working Group 3 of the European Medical ALARA Network (EMAN) project for insightful comments about the manuscript.

\section{References}

1 Dumonceau JM, Polkowski M, Larghi A et al. Indications, results, and clinical impact of endoscopic ultrasound (EUS)-guided sampling in gastroenterology: European Society of Gastrointestinal Endoscopy (ESGE) Clinical Guideline. Endoscopy 2011; 43: 897-912

2 Dumonceau JM, Andriulli A, Deviere J et al. European Society of Gastrointestinal Endoscopy (ESGE) Guideline: prophylaxis of post-ERCP pancreatitis. Endoscopy 2010; 42: 503-515

3 Harbour R, Miller J. A new system for grading recommendations in evidence based guidelines. BMJ 2001; 323: 334-336

4 International Commission on Radiation Units and Measurements. Fundamental quantities and units for ionizing radiation. ICRU Report 2011; 85:

5 International Electrotechnical Commission. Medical electrical equipment - Part 2-43: Particular requirements for the basic safety and essential performance of X-ray equipment for interventional procedures. 2010: IEC 60601-2-43. Ed. 2.0.

6 Council Directive 97/43/Euratom of 30 June 1997 on health protection of individuals against the dangers of ionizing radiation in relation to medical exposure, and repealing Directive 84/466/Euratom. Available at: http://ec.europa.eu/energy/nuclear/radioprotection/doc/legislation/9743_en.pdf Accessed: February 102011

7 Valentin J. Publication 103. The 2007 Recommendations of the International Commission on Radiological Protection.. Ann ICRP 2007; 37: $23-275$

8 European Commission. Radiation Protection 154. European Guidance on estimating population doses from medical X-ray procedures. Luxembourg: Directorate General for Energy and Transport; 2008

9 Valentin J. Relative biological effectiveness (RBE), quality factor ( $Q$ ), and radiation weighting factor (wR). ICRP Publication 92.. Ann ICRP 2003; 33: $1-121$

10 European Commission. Radiation Protection 116. Guidelines on education and training in radiation protection for medical exposures. Luxembourg: Directorate General Environment, Nuclear Safety and Civil Protection. 2000: Available at: http://eceuropaeu/energy/nuclear/radiation_protection/doc/publication/116pdf Accessed: December 21 2010

11 Teunen $D$. The European Directive on health protection of individuals against the dangers of ionising radiation in relation to medical exposures (97/43/EURATOM). J Radiol Prot 1998; 18: 133-137

12 Vano E, Gonzalez L, Canis M et al. Training in radiological protection for interventionalists. Initial Spanish experience.. Br J Radiol 2003; 76: 217

13 Rehani MM, Vano E, Ciraj-Bjelac $O$ et al. Radiation and cataract. Radiat Prot Dosimetry 2011; 147: 300 - 304 Epub 2011 Jul 14

14 Kleinerman RA. Cancer risks following diagnostic and therapeutic radiation exposure in children. Pediatr Radiol 2006; 36: 121-125

15 Buls N, Pages J, Mana $F$ et al. Patient and staff exposure during endoscopic retrograde cholangiopancreatography. Br J Radiol 2002; 75 : $435-443$

16 Chen MY, Van Swearingen FL, Mitchell $R$ et al. Radiation exposure during ERCP: effect of a protective shield. Gastrointest Endosc 1996; 43: $1-5$

17 Cohen G, Brodmerkel GJ, Lynn S. Absorbed doses to patients and personnel from endoscopic retrograde cholangiopancreatographic (ERCP) examinations. Radiology 1979; 130: 773 - 775

18 Germanaud J, Legoux JL, Sabattier $R$ et al. [Radiation protection of operators during endoscopic retrograde cholangiopancreatography]. Gastroenterol Clin Biol 1993; 17: 259-263
19 Heyd RL, Kopecky KK, Sherman S et al. Radiation exposure to patients and personnel during interventional ERCP at a teaching institution. Gastrointest Endosc 1996; 44: 287-292

20 Ismail S, Khan F, Sultan $N$ et al. Radiation exposure to anaesthetists during interventional radiology. Anaesthesia 2010; 65: 54-60

21 Johlin FC, Pelsang $R$, Greenleaf $M$. Phantom study to determine radiation exposure to medical personnel involved in ERCP fluoroscopy and its reduction through equipment and behavior modifications. Am J Gastroenterol 2002; 97: 893-897

22 Larkin CJ, Workman A, Wright RE et al. Radiation doses to patients during ERCP. Gastrointest Endosc 2001; 53: 161 - 164

23 Naidu LS, Singhal S, Preece DE et al. Radiation exposure to personnel performing endoscopic retrograde cholangiopancreatography. Postgrad Med J 2005; 81: 660-662

24 Samara ET, Stratakis J, Enele Melono JM et al. Therapeutic ERCP and pregnancy: is the radiation risk for the conceptus trivial? Gastrointest Endosc 2009; 69: 824-831

25 Selmaier M, Stillkrieg W, Müller RG et al. [Radiation burden in diagnostic and therapeutic endoscopic retrograde cholangiopancreatography (ERCP)]. Z Gastroenterol 1994; 32: 671 - 674

26 Tsalafoutas IA, Paraskeva KD, Yakoumakis EN et al. Radiation doses to patients from endoscopic retrograde cholangiopancreatography examinations and image quality considerations. Radiat Prot Dosimetry 2003; 106: 241 - 246

27 Uradomo LT, Lustberg ME, Darwin PE. Effect of physician training on fluoroscopy time during ERCP. Dig Dis Sci 2006; 51: 909-914

28 Vañó E, González L, Beneytez $F$ et al. Lens injuries induced by occupational exposure in non-optimized interventional radiology laboratories. Br J Radiol 1998; 71: $728-733$

29 Vano E, Kleiman NJ, Duran A et al. Radiation cataract risk in interventional cardiology personnel. Radiat Res 2010; 174: 490-495

30 Olgar T, Bor D, Berkmen $G$ et al. Patient and staff doses for some complex X-ray examinations. J Radiol Prot 2009; 29: 393-407

31 Brambilla M, Marano G, Dominietto $M$ et al. Patient radiation doses and references levels in interventional radiology. Radiol Med 2004; 107: $408-418$

32 Widmark A, Fosmark H, Einarsson G et al. Guidance levels in the Nordic countries: a preliminary report for selected interventional procedures. Radiat Prot Dosimetry 2001; 94: 133-135

33 Hart D, Hillier C, Wall B HPA-RPD-029. Doses to patients from radiographic and fluoroscopic X-ray imaging procedures in the UK - 2005 Review. Oxford, UK: Health Protection Agency; 2007: Avaiable at http://www.hpa.org.uk/webc/HPAwebFile/HPAweb_C/ 1194947413167 Accessed: September 272010.

34 Hart D, Hillier MC, Wall BF. National reference doses for common radiographic, fluoroscopic and dental X-ray examinations in the UK. Br J Radiol 2009; 82: 1-12

35 Amis E. Risks of radiation exposure in the endoscopy suite: principles, cautions, and risks to patients and endoscopy staff. Tech Gastrointest Endosc 2007; 9: 213-217

36 Pedrosa MC, Farraye FA, Shergill AK et al. Minimizing occupational hazards in endoscopy: personal protective equipment, radiation safety, and ergonomics. Gastrointest Endosc 2010; 72: 227-235

37 Campbell $N$, Sparrow $K$, Fortier $M$ et al. Practical radiation safety and protection for the endoscopist during ERCP. Gastrointest Endosc 2002; 55: $552-557$

38 Cousins C, Sharp C. Medical interventional procedures - reducing the radiation risks. Clin Radiol 2004; 59: 468-473

39 Järvinen $\mathrm{H}$, Buls $N$, Clerinx $P$ et al. Overview of double dosimetry procedures for the determination of the effective dose to the interventional radiology staff. Radiat Prot Dosimetry 2008; 129: 333 - 339

40 Cohen RV, Aldred MA, Paes WS et al. How safe is ERCP to the endoscopist? Surg Endosc 1997; 11: 615-617

41 Uradomo LT, Goldberg EM, Darwin PE. Time-limited fluoroscopy to reduce radiation exposure during ERCP: a prospective randomized trial. Gastrointest Endosc 2007; 66: 84-89

42 DomienikJ, Brodecki M, Carinou E et al. Extremity and eye lens doses in interventional radiology and cardiology procedures: first results of the ORAMED project. Radiat Prot Dosimetry 2011; 144: 442 - 447

43 Oonsiri S, Jumpangern C, Sanghangthum T et al. Radiation dose to medical staff in interventional radiology. J Med Assoc Thai 2007; 90: 823 828

44 Cordoliani YS. Organisation de la radioprotection dans un service d'imagerie médicale. Feuill Radiol 2004; 44: 381 - 387 
45 Miller DL, Balter S, Wagner LK et al. Quality improvement guidelines for recording patient radiation dose in the medical record. J Vasc Interv Radiol 2009; 20: 200 - 207

46 Valentin J. Avoidance of radiation injuries from medical interventional procedures, ICRP Publication 85. Ann ICRP 2000; 30: 51

47 U.S. Food and Drug Administration (FDA). Recording information in the patient's medical record that identifies the potential for serious X-Rayinduced skin injuries. Available at: www.fda.gov/Radiation-EmittingProducts/RadiationEmittingProductsandProcedures/MedicalImaging/ MedicalX-Rays/ucm117030htm Accessed September 22011

48 Balter S. Methods for measuring fluoroscopic skin dose. Pediatr Radiol 2006; 36: 136-140

49 Le Heron JC. Estimation of effective dose to the patient during medical $\mathrm{x}$-ray examinations from measurements of the dose-area product. Phys Med Biol 1992; 37: 2117 - 2126

50 U.S. Food and Drug Administration (FDA). Performance standard for diagnostic X-Ray systems and their major components. (21CFR 1020.30, 1020.31, 1020.32, 1020.33); Small entity compliance guide. 07. 06 2007: Available at: www.fda.gov/downloads/MedicalDevices/DeviceRegulationandGuidance/GuidanceDocuments/ucm094370.htm Accessed: August 232011

51 International Electrotechnical Commission (IEC). Medical electrical equipment - Part 1-2: General requirements for basic safety and essential performance - Collateral standard. Electromagnetic compatibility. Requirements and tests. IEC 60601-1-2. Ed. 3.0. 2007.

52 Miller DL, Balter S, Cole PE et al. Radiation doses in interventional radiology procedures: the RAD-IR study: part II: skin dose. J Vasc Interv Radiol 2003; 14: 977 - 990

53 Amis ES, Butler PF, Applegate KE et al. American College of Radiology white paper on radiation dose in medicine. J Am Coll Radiol 2007; 4: $272-284$

54 Baron TH, Schueler BA. Pregnancy and radiation exposure during therapeutic ERCP: time to put the baby to bed? Gastrointest Endosc 2009; 69: $832-834$

55 Kicken PJ, Bos AJ. Effectiveness of lead aprons in vascular radiology: results of clinical measurements. Radiology 1995; 197: 473-478

56 Rawlings DJ, Faulkner K, Harrison RM. Broad-beam transmission data in lead for scattered radiation produced at diagnostic energies. $\mathrm{Br} \mathrm{J}$ Radiol 1991; 64: 69-71

57 Schueler BA. Operator shielding: how and why. Tech Vasc Interv Radiol 2010; 13: 167 - 171

58 O'Sullivan S, Bridge G, Ponich T. Musculoskeletal injuries among ERCP endoscopists in Canada. Can J Gastroenterol 2002; 16: 369 - 374

59 Goldstein JA, Balter S, Cowley M et al. Occupational hazards of interventional cardiologists: prevalence of orthopedic health problems in contemporary practice. Catheter Cardiovasc Interv 2004; 63: 407-411

60 Ross AM, Segal J, Borenstein D et al. Prevalence of spinal disc disease among interventional cardiologists. Am J Cardiol 1997; 79: 68-70

61 Shergill AK, McQuaid KR, Rempel D. Ergonomics and GI endoscopy. Gastrointest Endosc 2009; 70: 145 - 153

62 Khalil MT, Abdel-Moty ME, Rosomoff SR, Rosomoff H. Ergonomics in back pain: a guide to prevention and rehabilitation. New York: Wiley; 1993

63 Yaffe MJ, Mawdsley GE, Lilley $M$ et al. Composite materials for x-ray protection. Health Phys 1991; 60: 661-664

64 Wagner LK, Mulhern OR. Radiation-attenuating surgical gloves: effects of scatter and secondary electron production. Radiology 1996; 200: $45-48$

65 Nicholson RA. Technical note: the relationship between TV position and the effectiveness and comfort of protective spectacles in fluoroscopic procedures. Br J Radiol 1995; 68: 1021 - 1024

66 Maeder M, Brunner-La Rocca HP, Wolber T et al. Impact of a lead glass screen on scatter radiation to eyes and hands in interventional cardiologists. Catheter Cardiovasc Interv 2006; 67: 18-23

67 Whitby M, Martin CJ. Radiation doses to the legs of radiologists performing interventional procedures: are they a cause for concern? $\mathrm{Br} \mathrm{J}$ Radiol 2003; 76: 321 - 327
68 Balter S. Radiation safety in the cardiac catheterization laboratory: operational radiation safety. Catheter Cardiovasc Interv 1999; 47: 347 353

69 Valentin J. Diagnostic radiology. Ann ICRP 2000; 30: 15 - 19

70 Atomic Energy Regulatory Board (AERB). Safety code for medical diagnostic X-ray equipment and installations, No. AERB/SC/MED-2 (Rev 1). Mumbai: AERB; 2001

71 Tsalafoutas IA, Yakoumakis E, Sandilos P. A model for calculating shielding requirements in diagnostic X-ray facilities. Br J Radiol 2003; 76 : $731-737$

72 National Council on Radiation Protection and Measurements (NCRP). Report No 147 - Structural shielding design for medical X-ray imaging facilities. Bethesda, Maryland, USA: NCRP; 2004

73 Archer BR, Gray JE. Important changes in medical x-ray imaging facility shielding design methodology. A brief summary of recommendations in NCRP Report No. 147. . Med Phys 2005; 32: 3599-3601

74 Damilakis J, Perisinakis $K$, Theocharopoulos $N$ et al. Anticipation of radiation dose to the conceptus from occupational exposure of pregnant staff during fluoroscopically guided electrophysiological procedures. J Cardiovasc Electrophysiol 2005; 16: 773 - 780

75 Jorgensen JE, Rubenstein JH, Goodsitt MM et al. Radiation doses to ERCP patients are significantly lower with experienced endoscopists. Gastrointest Endosc 2010; 72: 58 - 65

76 Hernandez RJ, Goodsitt MM. Reduction of radiation dose in pediatric patients using pulsed fluoroscopy. AJR Am J Roentgenol 1996; 167: $1247-1253$

77 Scanavacca $M$, d'Avila A, Velarde JL et al. Reduction of radiation exposure time during catheter ablation with the use of pulsed fluoroscopy Int J Cardiol 1998; 63: $71-74$

78 Boland GW, Murphy B, Arellano R et al. Dose reduction in gastrointestinal and genitourinary fluoroscopy: use of grid-controlled pulsed fluoroscopy. AJR Am J Roentgenol 2000; 175: 1453-1457

79 Sprawls $P$. Physical principles of medical imaging. Available at: www. sprawls.org/ppmi2/SCATRAD/\#CONTRAST Accessed: February 10 2011

80 Yanch JC, Behrman RH, Hendricks $M J$ et al. Increased radiation dose to overweight and obese patients from radiographic examinations. Radiology 2009; 252: $128-139$

81 Vehmas T. Hawthorne effect: shortening of fluoroscopy times during radiation measurement studies. Br J Radiol 1997; 70: 1053-1055

82 Nicholson $R$, Tuffee F, Uthappa MC. Skin sparing in interventional radiology: the effect of copper filtration. Br J Radiol 2000; 73: 36-42

83 Morrell RE, Rogers AT, Jobling JC et al. Barium enema: use of increased copper filtration to optimize dose and image quality. Br J Radiol 2004; 77: $116-122$

84 Balter S, Hopewell JW, Miller DL et al. Fluoroscopically guided interventional procedures: a review of radiation effects on patients' skin and hair. Radiology 2010; 254: 326 - 341

85 Hall EJ. Lessons we have learned from our children: cancer risks from diagnostic radiology. Pediatr Radiol 2002; 32: 700 - 706

86 Koenig TR, Mettler FA, Wagner LK. Skin injuries from fluoroscopically guided procedures: part 2, review of 73 cases and recommendations for minimizing dose delivered to patient. AJR Am J Roentgenol 2001; 177: $13-20$

87 Strauss KJ, Kaste SC. ALARA in pediatric interventional and fluoroscopic imaging: striving to keep radiation doses as low as possible during fluoroscopy of pediatric patients - a white paper executive summary. J Am Coll Radiol 2006; 3: 686-688

88 Romagnuolo J, Bardou M, Rahme E et al. Magnetic resonance cholangiopancreatography: a meta-analysis of test performance in suspected biliary disease. Ann Intern Med 2003; 139: 547 - 557

89 Garrow D, Miller S, Sinha D et al. Endoscopic ultrasound: a meta-analysis of test performance in suspected biliary obstruction. Clin Gastroenterol Hepatol 2007; 5: 616-623

Appendix 12 , and 3 and References 90-112 are available online:

online content viewable at:

www.thieme-connect.de/ejournals/abstract/endoscopy/

doi/10.1055/s-0031-1291791 